\title{
HABIT FORMATION, PRICE INDEXATION AND WAGE INDEXATION IN THE DSGE MODEL: SPECIFICATION, ESTIMATION AND MODEL FIT
}

\section{Martin Slanicay, Osvald Vašíček}

Masaryk University, Faculty of Economics and Administration, Department of Economics, Lipová 41a, Brno 602 00, slanicay@ mail.muni.cz, osvald@econ.muni.cz

\begin{abstract}
In order to determine which specification provides better fit of the data, this paper presents several specifications of a closed economy DSGE model with nominal rigidities. The goal of this paper is to find out whether some characteristics widely used in New Keynesian DSGE models, such as habit formation in consumption, price indexation and wage indexation, provide better fit of the macroeconomic data. Model specifications are estimated on the data of the US economy and Euro Area 12 economy, using Bayesian techniques, particularly the Metropolis-Hastings algorithm (using Dynare toolbox for Matlab). The data fit measure is a Bayes factor calculated from marginal likelihoods, acquired from Bayesian estimation. Results suggest that including habit formation in consumption significantly improves the empirical data fit of the model, whereas including partial price indexation and partial wage indexation does not improve the empirical data fit of the model. Variants with full price indexation and full wage indexation were the worst ones concerning their data fit.
\end{abstract}

Key words: New Keynesian DSGE model, habit formation, price indexation, wage indexation, model comparison, Bayes factor

JEL Classification: C51, E32, E52

DOI: $10.2478 / \mathrm{v} 10135-011-0008-9$ 


\title{
HABIT FORMATION, PRICE INDEXATION AND WAGE INDEXATION IN THE DSGE MODEL: SPECIFICATION, ESTIMATION AND MODEL FIT ${ }^{1}$
}

\author{
Martin Slanicay, Osvald Vašíček ${ }^{2}$
}

\section{Introduction}

New Keynesian DSGE models are favorite tools of macroeconomic modeling and are widely used by central banks for monetary policy analysis. There is a lot of different specifications of these models, with different assumptions and because of these different assumptions, behavior of a modelled economy can differ significantly . ${ }^{3}$ Justiniano and Preston (2004, p. 1) argue: However, despite this burgeoning theoretical literature, until recently, there has been little work on directly evaluating the ability of these DSGE models to fit open economy macroeconomic data.

The goal of this paper is to evaluate whether some features of New Keynesian DSGE models such as habit formation in consumption, price indexation and wage indexation improve their data fit. These features are widely used in New Keynesian DSGE models, see Christiano, Eichenbaum and Evans (2003), Smets and Wouters (2003), Liu (2006), Remo (2008), Justiniano and Preston (2010), Musil and Vašíček (2006) and many others. Fuhrer (2000) argues that including habit formation improves capturing gradual hump-shaped responses of consumption and inflation to various shocks. Assumption of partial price indexation and its consequences for inflation dynamics are discussed in many papers, see for example Galí and Gertler (1999) and Galí, Gertler and LopezSalido (2005). Including price indexation into Calvo constraint for firms makes inflation dynamics more adaptive and backward-looking. Under this assumption, present inflation does not depend only on expected future inflation but also on past inflation. Including wage indexation has a similar effect, wage inflation now depends on expected future wage inflation as well as on past price inflation. Smets and Wouters (2003) argue that including partial indexation makes DSGE models more robust for policy and welfare analysis. Justiniano and Preston (2010) estimate a DSGE model on the data of Australia, Canada and New Zealand and find that there is an evidence supporting the presence of habit formation only for Australia, while for all countries there is no evidence supporting the presence of price indexation. Matheson (2010) estimates a DSGE model extended by distinction between tradable and non-tradable sector on the data of Australia, Canada and New Zealand, and find (in contrast to Rabanal and RubioRamirez (2005)) that models with habit formation provide better data fit than those with partial price indexation, and that including partial price indexation deteriorates the empirical fit of the model. Similarly, Slanicay and Vašíček (2009) and Čapek (2010)

\footnotetext{
1 This work was supported by funding of specific research at ESF MU, project MUNI/A/0943/2009 and by MŠMT project Research centers 1M0524.

${ }^{2}$ Masaryk University, Faculty of Economics and Administration, Department of Economics, Lipová 41a, Brno 602 00, slanicay@ mail.muni.cz, osvald@econ.muni.cz

${ }^{3}$ Examples how assumptions which are examined in this study alter the behavior of DSGE models are presented in the next paragraph.
} 
estimate a DSGE model on the data of the Czech Republic and find that including habit formation improves the empirical fit of the model, whereas including partial price indexation deteriorates the empirical data fit.

So, we want to find out which specifications of the New Keynesian DSGE model provide a better fit of the data and evaluate whether some widely used features of New Keynesian models, such as habit formation, price indexation and wage indexation, improve their data fit. A simple closed economy DSGE model was chosen for this purpose. ${ }^{1}$ The model is based on the model from chapter 6 of Galí's textbook, see Galí (2008), which we extend in several ways. We allow for habit formation in consumption, price indexation and wage indexation. We also make some modifications in order to estimate the model on the detrended data. We also modify a monetary policy rule. All model specifications are estimated using Bayesian techniques, particularly the Metropolis-Hastings algorithm (using Dynare toolbox for Matlab). The comparison of alternative model variants is based on the Bayes factor, calculated from marginal likelihoods, acquired from Bayesian estimation.

\section{Model}

\section{Firms}

We assume a continuum of firms indexed by $i \in[0,1]$. Each firm produces its own differentiated product and hire labor. Production function of the firm $i \in[0,1]$ is in the form

$$
Y_{t}(i)=A_{t} N_{t}(i)^{1-\alpha}
$$

where $\alpha \in(0,1)$ is a parameter of decreasing returns to scale, $A_{t}$ is an exogenous technology process common to all firms and $N_{t}(i)$ is an index of labor input hired by the firm $i$ defined as

\footnotetext{
${ }^{1}$ The model is highly stylized and does not contain all the bells and whistles of DSGE models which are used in central banks. Nevertheless, despite its simplicity, it contains all the features that are necessary for our purpose, and this simplicity is in accordance with Occam's razor principle. The assumption of the closed economy is chosen because we want to test our hypothesis on the most reliable data available. In our opinion, the most reliable data are the data of the US economy and Euro Area 12 economy. Both economies can be regarded as approximately closed, so we decided (according to the Occam's razor principle) to use the closed economy model. Using a more complex model which contains various extensions such as richer production structure or some open economy features is not necessary because it provides similar results as this simple model. The evidence that assumption of a small open economy does not significantly alter the results is provided by Slanicay and Vašíček (2009) and Matheson (2010). Matheson (2010) also shows that richer production structure with distinction between tradable and non-tradable goods does not alter his results about habit formation and partial indexation.
} 


$$
N_{t}(i)=\left[\int_{0}^{1} N_{t}(i, j)^{1-\frac{1}{\varepsilon_{w}}} d j\right]^{\frac{\varepsilon_{w}}{\varepsilon_{w}-1}},
$$

where $N_{t}(i, j)$ denotes amount of labor type $j$ employed by the firm $i$ in period $t$ and $\varepsilon_{w}$ is an elasticity of substitution among different labor varieties. Cost minimization leads to a set of demand schedules for each firm $i$ and labor type $j$ in the form

$$
N_{t}(i, j)=\left(\frac{W_{t}(j)}{W_{t}}\right)^{-\varepsilon_{w}} N_{t}(i),
$$

where

$$
W_{t}=\left[\int_{0}^{1} W_{t}(j)^{1-\varepsilon_{w}} d j\right]^{\frac{1}{1-\varepsilon_{w}}}
$$

is an aggregate wage index. Firms seek to maximize the discounted sum of their current and expected future profits, taking into account their demand constraints and the Calvo constraint with partial indexation on the frequency of price adjustment. According to this type of Calvo constraint, every period, only $1-\theta_{p}$ portion of producers reset their prices optimally while a fraction $\theta_{p}$ adjust their prices according to an indexation rule

$$
P_{t+1}(i)=P_{t}(i)\left(\frac{P_{t}}{P_{t-1}}\right)^{\delta},
$$

where

$$
P_{t}=\left[\int_{0}^{1} P_{t}(i)^{1-\varepsilon_{p}} d i\right]^{\frac{1}{1-\varepsilon_{p}}}
$$

is an aggregate price index, $\boldsymbol{\varepsilon}_{p}$ is an elasticity of substitution among different goods, $P_{t}(i)$ is the price of the firm $i$ set in the period $t$ and $0<\delta_{p}<1$ is a parameter of price indexation. If we set $\delta_{p}=0$, we get the original Calvo constraint, see Calvo (1983), as presented in Galí (2008). If we set $\delta_{p}=1$, we get the Calvo constraint with a full price indexation, where all firms, which can not re-optimize their prices, fully 
adjust their prices according to past inflation. The maximalization problem of a firm resetting its price in period $t$ is then in the form ${ }^{1}$

$$
\max _{P_{t}^{*}} \sum_{k=0}^{\infty} \theta_{p}^{k} E_{t}\left\{Q_{t+k \mid t}\left(Y_{t+k \mid t} P_{t}^{*}\left(\frac{P_{t+k-1}}{P_{t-1}}\right)^{\delta_{p}}-\Psi_{t+k}\left(Y_{t+k \mid t}\right)\right)\right\}
$$

subject to the set of demand constraints

$$
Y_{t+k \mid t}=\left(\frac{P_{t}^{*}}{P_{t+k}}\left(\frac{P_{t+k-1}}{P_{t-1}}\right)^{\delta}\right)^{-\varepsilon} C_{t+k}, \quad k=0,1,2, \ldots,
$$

where $P_{t}^{*}$ is the price set in period $t$ by a firm reoptimizing its price in that period, $Y_{t+k \mid t}$ is the production of the firm in period $t+k$, that reset its price in period $t$ for the last time, $\Psi_{t+k}($.$) is the cost function of the firm in the period t+k$, and $Q_{t+k \mid t}=\beta^{k}\left(C_{t+k} / C_{t}\right)^{-\sigma}\left(P_{t} / P_{t+k}\right)$ is the stochastic discount factor for nominal payoffs. First order optimality condition for the maximalization problem of the firm is then in the form

$$
\sum_{k=0}^{\infty} \theta_{p}^{k} E_{t}\left\{Q_{t+k \mid t} Y_{t+k \mid t}\left(P_{t}^{*}\left(\frac{P_{t+k-1}}{P_{t-1}}\right)^{\delta_{p}}-\frac{\varepsilon_{p}}{\varepsilon_{p}-1} \psi_{t+k \mid t}\right)\right\}
$$

where $\psi_{t+k \mid t}$ are nominal marginal costs of the firm in the period $t+k$, that reset its price for the last time in the period $t$. This maximalization problem leads (after some mathematical manipulations ${ }^{2}$ ) to the relation between past inflation $\pi_{t-1}^{p}$, current inflation $\pi_{t}^{p}$, future expected inflation $E_{t}\left(\pi_{t+1}^{p}\right)$ and the gap of real marginal costs $\tilde{m} c_{t}$

$$
\pi_{t}^{p}=\beta E_{t}\left(\pi_{t+1}^{p}-\delta_{p} \pi_{t}^{p}\right)+\delta_{p} \pi_{t-1}^{p}+\lambda_{p} \tilde{m} c_{t}
$$

If we want to get the price Phillips curve as a relation between inflation and the output gap, we have to substitute the relation ${ }^{3}$ between the gap of real marginal costs $\tilde{m} c_{t}$, output gap $\tilde{y}_{t}$ and real wage gap $\tilde{\omega}_{t}$ into the (1). After adding a stochastic AR1 process $d_{t}$ to this equation, we get the price Phillips curve in the form

\footnotetext{
${ }^{1}$ Since we assume identical technology and symmetric preferences, all firms solve the same maximalization problem and we can omit index $i$.

${ }^{2}$ For detailed derivation see Remo (2008, p. 43-47).

${ }^{3}$ For detailed derivation of this relation see Galí (2008, ch. 6, p. 126). 


$$
\pi_{t}^{p}=\beta E_{t}\left(\pi_{t+1}^{p}-\delta_{p} \pi_{t}^{p}\right)+\delta_{p} \pi_{t-1}^{p}+\kappa_{p} \tilde{y}_{t}+\lambda_{p} \widetilde{\omega}_{t}+d_{t},
$$

where $\kappa_{p}=\frac{\alpha \lambda_{p}}{1-\alpha}$ and $\lambda_{p}=\frac{\left(1-\theta_{p}\right)\left(1-\beta \theta_{p}\right)}{\theta_{p}} \frac{1-\alpha}{1-\alpha+\alpha \varepsilon_{p}}$.

\section{Households}

We assume a continuum of households indexed by $j \in[0,1]$. Households consume goods produced by firms, trade bonds and provide labor to firms. Each household is specialized in a different kind of work and seeks to maximize its utility function

$$
E_{0} \sum_{t=0}^{\infty} \beta^{t} U_{t}\left(C_{t}(j), N_{t}(j)\right)
$$

where $E_{t}$ denotes expectations in the period $t, \beta$ is the discount factor, $N_{t}(j)$ is a quantity of labor supplied, and $C_{t}(j)$ is a consumption index of a household $j$ in the form

$$
C_{t}(j)=\left(\int_{0}^{1} C_{t}(i, j)^{1-\frac{1}{\varepsilon_{p}}} d i\right)^{\frac{\varepsilon_{p}}{\varepsilon_{p}-1}}
$$

where $\varepsilon_{p}$ is elasticity of substitution among different types of goods and $C_{t}(i, j)$ denotes consumption of a product $i$ by the household $j$ in the period $t$. A period utility function $U_{t}\left(C_{t}(j), N_{t}(j)\right)$ is in the form of a CRRA function with habit formation in consumption

$$
U_{t}=\frac{\left(C_{t}(j)-H_{t}\right)^{1-\sigma}}{1-\sigma}-\frac{N_{t}(j)^{1+\phi}}{1+\phi}
$$

where $\sigma>0$ is an inverse elasticity of intertemporal substitution in consumption, $\phi>0$ is an inverse elasticity of labor supply, $H_{t}=h C_{t-1}$ is an external habit taken as exogenous by households and $h \in(0,1)$ is a parameter of habit formation in consumption. If we set $h=0$ we get the standard CRRA period utility function, as presented in Galí (2008). 


\section{Optimal Labor Supply}

The model assumes the Calvo constraint with partial indexation on the frequency of wage adjustment, where only $1-\theta_{w}$ portion of households reset their wages optimally, while a fraction $\theta_{w}$ adjust their wages according to an indexation rule

$$
W_{t+1}(j)=W_{t}(j)\left(\frac{P_{t}}{P_{t-1}}\right)^{\delta_{w}},
$$

where $W_{t}(j)$ denotes the wage of the household $j$ in the period $t$ and $0<\delta_{w}<1$ is the parameter of wage indexation. If we set $\delta_{w}=0$, we get the original Calvo constraint, as presented in Galí (2008). If we set $\delta_{w}=1$, we get the Calvo constraint with full wage indexation, where all households, which can not re-optimize their wages, fully adjust their wages according to past price inflation. Let $W_{t}^{*}$ denotes a wage chosen by a household reoptimizing in the period $t$, then the household chooses $W_{t}^{*}$ in order to maximize ${ }^{1}$

$$
E_{t}\left\{\sum_{k=0}^{\infty}\left(\beta \theta_{w}\right)^{k} U\left(C_{t+k \mid t}, N_{t+k \mid t}\right)\right\},
$$

where $C_{t+k \mid t}$ and $N_{t+k \mid t}$ denote consumption and labor supply of households in the period $t+k$, if their last reoptimization was in the period $t$. Households maximize (2) subject to the set of labor demand constraints

$$
N_{t+k \mid t}=\left(\frac{W_{t}^{*}}{W_{t+k}}\left(\frac{P_{t+k-1}}{P_{t-1}}\right)^{\delta_{w}}\right)^{-\varepsilon_{w}} N_{t+k},
$$

and also subject to the set of their budget constraints

$P_{t+k} C_{t+k \mid t}+E_{t+k}\left\{Q_{t+k, t+k+1} D_{t+k+1 \mid t}\right\} \leq D_{t+k \mid t}+W_{t+k \mid t} N_{t+k \mid t}+T_{t+k} \quad k=0,1,2, \ldots$,

where $D_{t+k \mid t}$ is the market value in the period $t+k$ of a portfolio of securities held at the beginning of that period by household that last reoptimized its wage in period $t$, $E_{t+k}\left\{Q_{t+k, t+k+1} D_{t+k+1 \mid t}\right\}$ is a corresponding market value as of period $t+k$ of the portfolio purchased in that period, and which yields a random payoff $D_{t+k+1 \mid t}, W_{t+k \mid t}$ is a wage of a household in the period $t+k$ that last reoptimized its wage in the period $t$

${ }^{1}$ Since we assume symmetric preferences of households and complete markets, we can omit index $j$ in the following text. 
and $T_{t+k}$ are dividends from an ownership of the firms. First order optimality condition for the maximalization problem of households is then in the form

$$
\sum_{k=0}^{\infty}\left(\beta \theta_{w}\right)^{k} E_{t}\left\{N_{t+k \mid t} U_{c}\left(C_{t+k \mid t} N_{t+k \mid t}\right) \frac{W_{t}^{*}}{P_{t+k}}\left(\frac{P_{t+k-1}}{P_{t-1}}\right)^{\delta_{w}}+M_{w} U_{n}\left(C_{t+k \mid t} N_{t+k \mid t}\right)\right\},
$$

where $M_{w}=\frac{\varepsilon_{w}}{\varepsilon_{w}-1}$ is a desired wage mark-up. After some mathematical manipulations ${ }^{1}$ we get the relation between current wage inflation $\pi_{t}^{w}$, future expected wage inflation $E_{t}\left\{\pi_{t+1}^{w}\right\}$, past and present price inflations $\pi_{t-1}$ and $\pi_{t}$ and the wage mark-up gap $\tilde{\mu}_{t}^{w}$

$$
\pi_{t}^{w}=\beta E_{t}\left(\pi_{t+1}^{w}-\delta_{w} \pi_{t}\right)+\delta_{w} \pi_{t-1}-\lambda_{w} \tilde{\mu}_{t}^{w},
$$

where $\lambda_{w}=\frac{\left(1-\theta_{w}\right)\left(1-\beta \theta_{w}\right)}{\theta_{w}\left(1+\varepsilon_{w} \phi\right)}, \quad \mu^{w}=\log M_{w} \quad$ and $\quad \tilde{\mu}_{t}^{w}=\mu_{t}^{w}-\mu^{w} \quad$ denotes deviation of economy's (log) average wage mark-up from its steady state level (wage mark-up gap). Then we have to derive the relation ${ }^{2}$ between the wage mark-up gap $\widetilde{\mu}_{t}^{w}$, output gap $\tilde{y}_{t}$ and real wage gap $\tilde{\omega}_{t}$ in the form

$$
\tilde{\mu}_{t}^{w}=\tilde{\omega}_{t}-\left(\left(\frac{\sigma}{1-h}+\frac{\phi}{1-\alpha}\right) \tilde{y}_{t}-\frac{\sigma h}{1-h} \tilde{y}_{t-1}\right),
$$

and after substituting (4) into (3) and adding stochastic AR1 process $f_{t}$ we get the wage Phillips curve in the form

$$
\pi_{t}^{w}=\beta E_{t}\left(\pi_{t+1}^{w}-\delta_{w} \pi_{t}\right)+\delta_{w} \pi_{t-1}+\kappa_{w} \tilde{y}_{t}-v_{w} \tilde{y}_{t-1}-\lambda_{w} \tilde{\omega}_{t}+f_{t},
$$

where $\kappa_{w}=\lambda_{w}\left(\frac{\sigma}{1-h}+\frac{\phi}{1-\alpha}\right)$ and $v_{w}=\lambda_{w} \frac{\sigma h}{1-h}$.

\footnotetext{
${ }^{1}$ For detailed derivation see Galí (2008, ch. 6, p. 122-125) who presents a derivation without wage indexation. Derivation with wage indexation is very similar and the only changes in the equation (3) are positive weights on past and present price inflation.

${ }^{2}$ For detailed derivation of this relation see Appendix. Because of the presence of habit formation, this derivation is slightly different from that presented in Galí (2008, p. 126).
} 


\section{Optimal Intertemporal Decision}

Optimality condition for intertemporal decisions of households about consumption is in the form

$$
\frac{1}{1+i_{t}}=\beta E_{t}\left\{\left(\frac{C_{t+1}-h C_{t}}{C_{t}-h C_{t-1}}\right)^{-\sigma} \frac{P_{t}}{P_{t+1}}\right\},
$$

where $i_{t}$ is the nominal interest rate. Then using log-linear approximation we get

$$
c_{t}-h c_{t-1}=E_{t}\left\{c_{t+1}-h c_{t}\right\}-\frac{1-h}{\sigma}\left(i_{t}-E_{t}\left\{\pi_{t+1}\right\}\right) .
$$

If we apply market clearing condition $c_{t}=y_{t}$, rewrite equation for the output gap and add stochastic AR1 process $u_{t}$, we get the Euler equation in the form ${ }^{1}$

$$
\tilde{y}_{t}-h \tilde{y}_{t-1}=E_{t}\left\{\tilde{y}_{t+1}-h \tilde{y}_{t}\right\}-\frac{1-h}{\sigma}\left(i_{t}-E_{t}\left\{\pi_{t+1}^{p}\right\}\right)+u_{t} .
$$

\section{Inflation Identity and Monetary Policy Rule}

Wage inflation, price inflation and the real wage gap are connected in an identity

$$
\tilde{\omega}_{t}=\tilde{\omega}_{t-1}+\pi_{t}^{w}-\pi_{t}^{p}
$$

The model is completed with a monetary policy rule in the form of the modified Taylor rule

$$
i_{t}=\rho_{i} i_{t-1}+\left(1-\rho_{i}\right)\left[\psi_{\pi} \pi_{t}^{p}+\psi_{y} \tilde{y}_{t}\right]+\varepsilon_{v, t}
$$

where $\rho_{i}$ is a backward-looking parameter for the interest rate, $\psi_{\pi}$ is an elasticity of interest rate to inflation, $\psi_{y}$ is an elasticity of interest rate to output, and $\varepsilon_{v, t}$ is a monetary shock in the form of IID process.

\section{Estimation}

\section{Data of Euro Area 12}

Quarterly data of Euro Area 12 from 2nd Quarter 1996 to 2nd Quarter 2010 downloaded from the database of Eurostat, http://ec.europa.eu/eurostat

- $\tilde{y}_{t}$ : detrended data (linear trend used) of log real GDP per capita. A measure of GDP is Gross Domestic Product at Market Prices, Millions of Euro, Chain-linked Volumes,

\footnotetext{
${ }^{1}$ For detailed derivation see Musil and Vašíček (2006, p. 84-86) or Remo (2008, p. 47-50).
} 
Reference Year 2000 (at 2000 Exchange Rates), Seasonally Adjusted and Adjusted Data by Working Days. A measure of population is Total Population EU12.

- $\pi_{t}^{p}$ : demeaned data of quarterly price inflation rate. An underlying index for price inflation is Price Index of Gross Domestic Product at Market Prices, 2000=100, Based on Euro, Seasonally Adjusted and Adjusted Data by Working Days. Mean of quarterly price inflation rate is $0.43 \%$ and this value roughly corresponds to the official annual inflation target of $2 \%$.

- $\pi_{t}^{w}$ : demeaned data of quarterly wage inflation rate. From 2nd Quarter 1996 to 1 st Quarter 2000 is wage inflation calculated from Labour Cost Index $(2000=100)$ - Wages and Salaries, Industry and Services (excluding Public Administration), Seasonally Adjusted and Adjusted Data by Working Days. From 2nd Quarter 2000 to 2nd Quarter 2010 is wage inflation calculated from Labour Cost Index (Nace Rev.2) (2008=100) Wages and Salaries, Business Economy, Seasonally Adjusted and Adjusted Data by Working Days.

- $i_{t}$ : demeaned data of quarterlized nominal interest rate. A measure of nominal interest rate is Money Market Interest Rates, 3-Month Rates.

\section{Data of the USA}

Quarterly data of the USA from 1st Quarter 1985 to 2nd Quarter 2010 downloaded from the database of FRED (Federal Reserve Economic Data), http://research.stlouisfed.org/fred2

- $\tilde{y}_{t}$ : detrended data (linear trend used) of log real GDP per capita. A measure of GDP is GDPC1: Real Gross Domestic Product, in Billions of Chained 2000 Dollars, Seasonally Adjusted Annual Rate. A measure of population is POP: Total Population: All Ages including Armed Forces Overseas.

- $\pi_{t}^{p}$ : demeaned data of quarterly price inflation rate. An underlying index for price inflation is CPIAUCSL: Consumer Price Index For All Urban Consumers: All Items, Index 1982-84=100, Seasonally Adjusted.

- $\pi_{t}^{w}$ : demeaned data of quarterly wage inflation rate. An underlying index for wage inflation is COMPNFB: Nonfarm Business Sector: Compensation Per Hour, Index 1992=100, Seasonally Adjusted.

- $i_{t}$ : demeaned data of quarterlized nominal interest rate. A measure of nominal interest rate is TB3MS: 3-Month Treasury Bill: Secondary Market Rate, Averages of Business Days, Discount Basis. 


\section{Estimated Parameters}

Definition of parameters is in the Table 2. Except for three parameters $\left(\beta, \varepsilon_{p}, \mathcal{E}_{w}\right)$, which are difficult to identify and most literature calibrate them, all parameters are estimated using the Metropolis-Hastings algorithm (using Dynare toolbox for Matlab). The discount factor $\beta$ is calibrated to be 0.9975 , which implies an annual steady state real interest rate of $1 \%$. This value roughly corresponds to the long term mean of an annual real interest rate in both economies in the examined period. Elasticities of substitution between various goods $\mathcal{E}_{p}$ and labor inputs $\mathcal{E}_{w}$ are both set equal to 8 , following results reported in Woodford (2003, ch. 3), and imply an average price and wage mark-up of $14 \%$. Prior setting of estimated parameters as well as their estimated values (in the best variant concerning Bayes factor and in the baseline variant) are presented in Tables 3 and 4. Prior means for Calvo parameters $\theta_{p}$ and $\theta_{w}$ are set to be 0.7 and 0.75 , which implies an average price contract duration of 10 months $^{1}$ and average wage contract duration of one year. ${ }^{2}$ Estimated values of these parameters are a little bit higher and imply an average price duration of 11.5 months for the Euro Area and 13 months for the USA, and average wage duration of 15 months for the Euro Area and 17 months for the USA. Due to microeconomic evidence on price and wage indexation not being existent, we set very loose priors for these parameters, prior means equal to 0.5 with std. deviations equal to 0.2. Priors for parameters in Taylor rule are set consistently with Taylor (1999b). Although prior means for elasticities of interest rate to output $\psi_{y}$ and $\psi_{y}^{*}$ are set to be a little bit higher ( 0.2 instead of 0.125$)$, they take into account changes in behavior of central banks in recent crises. In our opinion, at this time central banks (ECB and FED) pay more attention to development in output than they did before the crisis. Inverse elasticities of intertemporal substitution $\sigma$ and labor supply $\phi$ are estimated with relatively loose priors with prior means set to be 1.0, consistently with Galí (2008), and std. deviations equal to 0.5. Prior mean for decreasing returns to scale $\alpha$ is set to be 0.33 , according to Galí (2008). Parameter of habit formation $h$ is estimated with prior mean set to be 0.7 , as in Smets and Wouters (2003). Backward-looking parameters in AR1 processes for exogenous shocks are estimated with very loose priors, prior means equal to 0.5 , and std. deviations equal to 0.2 .

\footnotetext{
${ }^{1}$ Nakamura and Steinson (2008)

2 Taylor (1999a)
} 


\section{Model Comparison}

\section{Bayes Factor}

The model comparison is based on the Bayes factor $(\mathrm{BF}) .{ }^{1}$ The Bayes factor of model $i$ and $j\left(B F_{i j}\right)$ is a Bayesian statistics calculated from log-likelihood functions ${ }^{2}$ (acquired from Bayesian estimation) as

$$
B F_{i j}=\frac{p\left(Y_{T} \mid M_{i}\right)}{p\left(Y_{T} \mid M_{j}\right.}=\exp \left(\log \left(p\left(Y_{T} \mid M_{i}\right)\right)-\log \left(p\left(Y_{T} \mid M_{j}\right)\right)\right),
$$

where $p\left(Y_{T} \mid M_{i}\right)$ is a likelihood function of model $i$ and $\log \left(p\left(Y_{T} \mid M_{i}\right)\right)$ is a $\log$ likelihood function of model $i{ }^{3}$ The Bayes factor shows us how much more probable is the model $i$ than the model $j$. DeJong and Dave (2007, p. 242) show an interpretation ${ }^{4}$ of $B F$ values

- 1-3 - "very slight evidence"

- 3-10 - "slight evidence"

- $\quad$ 10-100 - "strong to very strong evidence"

- $\quad 100$ and higher - "decisive evidence"

This interpretation shows us how strong the evidence of the Bayes factor about that whether model $i$ explains the data better then model $j$ is. It is obvious that holds $B F_{M i / M j}=1 / B F_{M j / M i}$.

It is worth mentioning why we chose this Bayesian method for model comparison, based on comparison of likelihood functions. Other methods used for model comparison focus only on some aspects of the data fit. On the contrary, model comparison based on likelihood functions compares overall data fit of the model. Loosely speaking, likelihood function $p\left(Y_{T} \mid M i\right)$ measures how well the model $i$ predicts the observed data $Y_{T}$. Author of this essay think that this method provides the most comprehensive results about the data fit of DSGE models.

\footnotetext{
${ }^{1}$ The Bayes factor is a specific case of posterior odds (PO) where prior probabilities of competing models are set as equal. Because compared specifications of the model are nested, it is correct to set prior probabilities as equal.

${ }^{2}$ Calculation of log-likelihood functions is based on the Laplace approximation.

${ }^{3}$ It is more convenient to use log-likelihood functions, as their computation is much easier. In the following text we display our results using log-likelihood functions.

${ }^{4}$ Similar interpretation can be found in Jeffreys (1961) or Kass and Raftery (1995).
} 


\section{Results}

Log-likelihood functions of particular variants are displayed in Table 1. Variants are ordered from the best to the worst, according to the EA 12 data fit. ${ }^{1}$ If we compare comparable variants ${ }^{2}$ which differ only in the assumption about $h$, than variants with habit formation in consumption $(h \in(0,1))$ are always better than variants with an assumption of no habit formation $(h=0)$. We can calculate Bayes factors for variants which differ only in the assumption about $h$. All Bayes factors are much higher than 100. On the basis of the interpretation of BF values presented above, we can say that there is a decisive evidence that including habit formation in consumption into the utility function of households improves the data fit of DSGE models significantly. A look on impulse-responses, see Figure 1, suggests that variant with the assumption of a habit formation in consumption displays more gradual and hump-shaped responses of output to various shocks.

Upon comparing comparable variants, where the only difference is the assumption about price indexation, we may see that variants with no indexation $\left(\delta_{p}=0\right)$ are always better than variants with partial indexation $\left(\delta_{p} \in(0,1)\right)$. Bayes factors between comparable variants with no indexation and variants with partial indexation are always higher than 10. Estimated values of the parameter of partial price indexation $\delta_{p}$ are very low. Impulse-responses of comparable models with no indexation and with partial indexation do not show almost any difference, see Figure 2, so we can say that the assumption of partial price indexation is - loosely speaking - redundant for plausible fit of DSGE models. We can say that there is a strong evidence that including partial price indexation into the Calvo constraint for firms does not improve the data fit of DSGE models. We can also see that comparable variants with partial price indexation ( $\left.\delta_{p} \in(0,1)\right)$ are always better than comparable variants with full price indexation ( $\delta_{p}=1$ ). Bayes factors between comparable variants with partial price indexation and variants with full price indexation are much higher than 100. Results suggest that the worst variants of the Calvo constraint for firms (concerning their data fit) are those with full price indexation.

Similar result stands for wage indexation. In comparison of comparable variants, we can see that variants with no wage indexation $\left(\delta_{w}=0\right)$ are always better than variants with partial wage indexation $\left(\delta_{w} \in(0,1)\right.$ ) and the latter are always better than variants with full wage indexation $\left(\delta_{w}=1\right.$ ). Bayes factors between comparable variants with no wage indexation and variants with partial wage indexation are mostly higher than 10 and in few cases around 10. Estimated values of the parameter of partial wage

\footnotetext{
${ }^{1}$ If we order variants according to the US data fit, there will be some minor differences in the sequence of variants. Nevertheless, the main patterns and consequent results remain the same.

${ }^{2}$ Comparable variants are variants which differ only in the examined assumption and other features of the model remain the same.
} 
indexation $\delta_{w}$ are very low and impulse-responses of comparable models with no indexation and with partial indexation do not show almost any difference, see Figure 2. Results suggest that there is a strong evidence that including partial wage indexation into the Calvo constraint of households does not improve the data fit of DSGE models. Bayes factors between comparable variants with partial wage indexation and variants with full wage indexation are always much higher than 100 . We can say that the worst variants of the Calvo constraint for households are those with full wage indexation.

Table 1: Log-likelihood of Alternative Variants

\begin{tabular}{|c|c|c|c|}
\hline$i$ & variant & $\begin{array}{c}\log \left(p\left(Y_{T} \mid M_{i}\right)\right) \\
\text { EA } 12\end{array}$ & $\begin{array}{c}\log \left(p\left(Y_{T} \mid M_{i}\right)\right) \\
\text { USA }\end{array}$ \\
\hline 1 & $\delta_{p}=0, \delta_{w}=0$ & -29.93 & -244.04 \\
\hline 2 & $\delta_{p}=0$ & -32.24 & -247.48 \\
\hline 3 & $\delta_{w}=0$ & -32.65 & -247.83 \\
\hline 4 & baseline & -35.02 & -251.27 \\
\hline 5 & $\delta_{p}=1, \delta_{w}=0$ & -40.52 & -264.94 \\
\hline 6 & $\delta_{p}=1$ & -42.70 & -268.48 \\
\hline 7 & $\delta_{p}=0, \delta_{w}=1$ & -49.66 & -270.86 \\
\hline 8 & $\delta_{w}=1$ & -52.90 & -274.84 \\
\hline 9 & $h=0, \delta_{p}=0, \delta_{w}=0$ & -56.34 & -277.51 \\
\hline 10 & $h=0, \delta_{w}=0$ & -59.54 & -281.62 \\
\hline 11 & $h=0, \delta_{p}=0$ & -59.57 & -281.41 \\
\hline 12 & $\delta_{p}=1, \delta_{w}=1$ & -61.50 & -292.82 \\
\hline 13 & $h=0$ & -62.82 & -285.55 \\
\hline 14 & $h=0, \delta_{p}=1, \delta_{w}=0$ & -67.79 & -298.79 \\
\hline 15 & $h=0, \delta_{p}=1$ & -70.89 & -302.93 \\
\hline 16 & $h=0, \delta_{p}=0, \delta_{w}=1$ & -80.06 & -306.64 \\
\hline 17 & $h=0, \delta_{w}=1$ & -83.79 & -311.25 \\
\hline 18 & $h=0, \delta_{p}=1, \delta_{w}=1$ & -91.79 & -328.93 \\
\hline
\end{tabular}

Note: Own calculations 


\section{Conclusion}

Results suggest that including habit formation in consumption into the utility function of households improves the empirical data fit of DSGE models significantly . Bayes factors between variants with habit formation and variants with no habit formation are so high that it provides decisive evidence for this conclusion. Impulse-responses suggest that the assumption of habit formation in consumption makes responses of output to various shocks more gradual and hump-shaped.

We can also see that including partial price indexation and partial wage indexation does not improve empirical data fit of DSGE models, although the calculated Bayes factors do not provide decisive evidence for this conclusion, only strong evidence. Parameters of partial indexation are estimated as very low and impulse-responses suggest that these assumptions can be viewed as redundant for plausible data fit of DSGE models.

The worst model variants, regarding the data fit of the model, are those with full price indexation and full wage indexation. Calculated Bayes factors provide decisive evidence for this conclusion.

\section{References}

CALVO, G. (1983). Staggered Prices in a Utility Maximizing Framework. Journal of Monetary Economics. 12(3), pp. 383-398.

CHRISTIANO, L. J., EICHENBAUM, M., EVANS, C. L. (2005). Nominal Rigidities and the Dynamic Effects of a Shock to Monetary Policy. Journal of Political Economy. 113(1), pp. 1-45. DOI: $10.1086 / 426038$

ČAPER, J. (2010). Comparing the fit of New Keynesian DSGE models. Ekonomická revue - Central European Review of Economic Issues. 13(4), pp. 207-218.

DeJONG, D. N., DAVE, C. (2007). Structural Macroeconometrics. New Jersey: Princeton University Press.

FUHRER, J. C. (2000). Habit Formation in Consumption and Its Implications for Monetary-Policy Models. American Economic Review. 90(3), pp. 367-390.

GALÍ, J. (2008). Monetary Policy, Inflation, and the Business Cycle: An Introduction to the New Keynesian Framework. New Jersey: Princeton University Press.

GALÍ, J., GERTLER, M., LOPEZ-SALIDO, D. J. (2005). Robustness of the Estimates of the Hybrid New Keynesian Phillips Curve. Journal of Monetary Economics. 52(6), pp. 1107-1118. DOI:10.1016/j.jmoneco.2005.08.005

GALÍ, J., GERTLER, M. (1999). Inflation Dynamics: A Structural Economic Analysis. CEPR Discussion Papers 2246.

JEFFREYS, H. (1961). Theory of Probability. Oxford: Oxford University Press.

JUSTINIANO, A., PRESTON, B. (2004). Small Open Economy DSGE models: Specification, Estimation and Model Fit. Working paper, Department of Economics, Columbia University. 
JUSTINIANO, A., PRESTON, B. (2010). Can Structural Small Open Economy Models Account for the Influence of Foreign Disturbances? Journal of International Economics. 81(1), pp. 61-74. DOI:10.1016/j.jinteco.2010.01.001

KASS, R. E., RAFTERY, A. E. (1995). Bayes Factors. Journal of the American Statistical Association. 90(430), pp. 773-795.

LIU, P. (2006). A Small New Keynesian Model of the New Zealand Economy. Reserve Bank of New Zealand, Discussion Paper Series DP 2006/03.

MATHESON, T. D. (2010). Assessing the Fit of Small Open Economy DSGEs. Journal of Macroeconomics. 32(3), pp. 906-920. DOI: 10.1016/j.jmacro.2009.10.001

MUSIL, K., VAŠÍČEK, O. (2006). Behavior of the Czech Economy: New Open Economy Macroeconomics DSGE Model. CVKS MU, Working paper No. 23/2006.

NAKAMURA, E., STEINSSON, J. (2008). Five Facts about Prices: A Reevaluation of Menu Costs Models. The Quarterly Journal of Economics. 123(4), pp. 1415-1464. DOI: 10.1162/qjec.2008.123.4.1415

RABANAL, P., RUBIO-RAMIREZ, J. (2005). Comparing New Keynesian Models of the Business Bycle: A Bayesian Approach. Journal of Monetary Economics. 52(6), pp. 1151-1166. DOI:10.1016/j.jmoneco.2005.08.008

REMO, A. (2008). Monetary Policy and Stability of Czech Economy: Optimal Commitment Policy in NOEM DSGE Framework. CVKS MU, Working paper No. $25 / 2008$.

SLANICAY, M., VAŠÍČEK, O. (2009). Porovnání různých specifikací novokeynesiánského DSGE modelu malé otevřené ekonomiky pro ČR." In Slaný (ed.): Ekonomické prostředí a konkurenceschopnost (pp. 203-216). Brno: CVKS MU.

SMETS, F., Wouters, R. (2003). An Estimated Dynamic Stochastic General Equilibrium Model of the Euro Area. Journal of the European Economic Association. 1(5), pp. 1123-1175.

TAYLOR, J. B. (1999a). Staggered Price and Wage Setting in Macroeconomics. In Taylor and Woodford (eds.), Handbook of Macroeconomics (chap. 15, 1341-1397). New York: Elsevier.

TAYLOR, J. B. (1999b). A Historical Analysis of Monetary Policy Rules. In Taylor (ed.), Monetary Policy Rules. Chicago: University of Chicago Press.

WOODFORD, M. (2003). Interest and Prices: Foundations of a Theory of Monetary Policy. New Jersey: Princeton University Press. 


\section{Appendix}

Derivation of the relation between the wage mark-up gap $\tilde{\mu}_{t}^{w}$, real wage gap $\tilde{\omega}_{t}$ and output gaps $\tilde{y}_{t}, \tilde{y}_{t-1}$ for the wage Phillips curve

From definition holds

$$
\tilde{\mu}_{t}^{w}=\mu_{t}^{w}-\mu^{w}
$$

where $\mu^{w}$ is steady state value of (log) wage mark-up and $\mu_{t}^{w}$ is economy's average wage mark-up in period $t$ defined as

$$
\mu_{t}^{w}=\omega_{t}-m r s_{t}
$$

where $\omega_{t}$ is $\log$ of real wage and $m r s_{t}=\log M R S_{t}$, where $M R S_{t}=-\frac{U_{n}}{U_{c}}$. Combining (6) and (7) we obtain

$$
\tilde{\mu}_{t}^{w}=\tilde{\omega}_{t}-m \tilde{r} s_{t}
$$

After substituting from definition of $m \tilde{r} s_{t}$ we obtain

$$
\tilde{\mu}_{t}^{w}=\tilde{\omega}_{t}-\left(\frac{\sigma}{1-h}\left(\tilde{y}_{t}-h \tilde{y}_{t-1}\right)+\phi \tilde{n}_{t}\right)
$$

Combining with approximate relation from production function ${ }^{1} \tilde{n}_{t}=\frac{\tilde{y}_{t}}{1-\alpha}$ we get

$$
\tilde{\mu}_{t}^{w}=\tilde{\omega}_{t}-\left(\left(\frac{\sigma}{1-h}+\frac{\phi}{1-\alpha}\right) \tilde{y}_{t}-\frac{\sigma h}{1-h} \tilde{y}_{t-1}\right)
$$

Substituting (8) into following relation

$$
\pi_{t}^{w}=\beta E_{t}\left(\pi_{t+1}^{w}-\delta_{w} \pi_{t}\right)+\delta_{w} \pi_{t-1}-\lambda_{w} \tilde{\mu}_{t}^{w}
$$

and adding stochastic AR1 process $f_{t}$ for wage inflation shock we obtain wage Phillips curve in the form

$$
\pi_{t}^{w}=\beta E_{t}\left(\pi_{t+1}^{w}-\delta_{w} \pi_{t}\right)+\delta_{w} \pi_{t-1}+\kappa_{w} \tilde{y}_{t}-v_{w} \tilde{y}_{t-1}-\lambda_{w} \tilde{\omega}_{t}+f_{t} .
$$

\footnotetext{
${ }^{1}$ Because we are adding stochastic AR1 process $f_{t}$ into the wage equation, ${ }_{t}$ can be omitted.
} 
Tables and Figures

Table 2: Definition of Parameters

\begin{tabular}{|c|c|c|}
\hline parameter & interpretation & restriction \\
\hline$\beta$ & discount factor & $\langle 0,1\rangle$ \\
\hline$\varepsilon_{p}$ & elasticity of substitution among different goods & $\langle 1, \infty)$ \\
\hline$\varepsilon_{w}$ & elasticity of substitution among labor varieties & $\langle 1, \infty)$ \\
\hline$\sigma$ & inv. elasticity of intertemporal substitution & $\langle 0, \infty)$ \\
\hline$\phi$ & inv. elasticity of labor supply & $\langle 0, \infty)$ \\
\hline$h$ & degree of habit formation in consumption & $\langle 0,1\rangle$ \\
\hline$\alpha$ & parameter of decreasing returns to scale & $\langle 0,1\rangle$ \\
\hline$\theta_{p}$ & fraction of non-optimizing firms & $\langle 0,1\rangle$ \\
\hline$\theta_{w}$ & fraction of non-optimizing households & $\langle 0,1\rangle$ \\
\hline$\delta_{p}$ & degree of price indexation & $\langle 0,1\rangle$ \\
\hline$\delta_{w}$ & degree of wage indexation & $\langle 0,1\rangle$ \\
\hline$\psi_{\pi}$ & elasticity of interest rate to inflation & $\langle 0, \infty)$ \\
\hline$\psi_{y}$ & elasticity of interest rate to output & $\langle 0, \infty)$ \\
\hline$\rho_{i}$ & backward-looking parameter for interest rate & $\langle 0,1\rangle$ \\
\hline$\rho_{u}$ & AR1 parameter for Euler equation shock & $\langle 0,1\rangle$ \\
\hline$\rho_{d}$ & AR1 parameter for price inflation shock & $\langle 0,1\rangle$ \\
\hline$\rho_{f}$ & AR1 parameter for wage inflation shock & $\langle 0,1\rangle$ \\
\hline$\sigma_{u}$ & std. deviation of Euler equation shock & $\langle 0, \infty)$ \\
\hline$\sigma_{v}$ & std. deviation of interest rate shock & $\langle 0, \infty)$ \\
\hline$\sigma_{d}$ & std. deviation of price inflation shock & $\langle 0, \infty)$ \\
\hline$\sigma_{f}$ & std. deviation of wage inflation shock & $\langle 0, \infty)$ \\
\hline
\end{tabular}


Table 3: Estimated Parameters - Best Variant: Habit Formation, No Indexation

\begin{tabular}{|c|c|c|c|c|c|c|c|}
\hline par. & $\begin{array}{l}\text { prior } \\
\text { mean }\end{array}$ & $\begin{array}{l}\text { prior } \\
\text { s. d. }\end{array}$ & $\begin{array}{l}\text { prior } \\
\text { dist. }\end{array}$ & $\begin{array}{c}\text { post. } \\
\text { mean } \\
\text { EA } 12\end{array}$ & $\begin{array}{c}90 \% \text { conf. } \\
\text { interval } \\
\text { EA } 12\end{array}$ & $\begin{array}{l}\text { post. } \\
\text { mean } \\
\text { USA }\end{array}$ & $\begin{array}{c}90 \% \text { conf. } \\
\text { interval } \\
\text { USA }\end{array}$ \\
\hline$\sigma$ & 1.0 & 0.5 & gamma & 1.26 & 0.521 .96 & 1.61 & 0.752 .46 \\
\hline$\phi$ & 1.0 & 0.5 & gamma & 1.30 & 0.472 .11 & 1.38 & 0.522 .18 \\
\hline$h$ & 0.7 & 0.1 & beta & 0.79 & 0.700 .89 & 0.76 & 0.650 .86 \\
\hline$\alpha$ & 0.33 & 0.1 & beta & 0.35 & 0.190 .50 & 0.41 & 0.260 .56 \\
\hline$\theta_{p}$ & 0.7 & 0.05 & beta & 0.74 & 0.680 .80 & 0.77 & 0.710 .83 \\
\hline$\theta_{w}$ & 0.75 & 0.05 & beta & 0.81 & 0.760 .86 & 0.83 & 0.780 .88 \\
\hline$\psi_{\pi}$ & 1.5 & 0.15 & gamma & 1.40 & 1.161 .63 & 1.39 & 1.181 .62 \\
\hline$\psi_{y}$ & 0.5 & 0.15 & gamma & 0.19 & 0.080 .30 & 0.15 & 0.060 .24 \\
\hline$\rho_{i}$ & 0.8 & 0.05 & beta & 0.89 & 0.860 .93 & 0.92 & 0.900 .94 \\
\hline$\rho_{u}$ & 0.5 & 0.2 & beta & 0.77 & 0.650 .89 & 0.89 & 0.830 .96 \\
\hline$\rho_{d}$ & 0.5 & 0.2 & beta & 0.37 & 0.180 .56 & 0.30 & 0.140 .46 \\
\hline$\rho_{f}$ & 0.5 & 0.2 & beta & 0.27 & 0.090 .44 & 0.18 & 0.060 .30 \\
\hline$\sigma_{u}$ & 0.1 & $\infty$ & i. gamma & 0.17 & 0.100 .23 & 0.09 & 0.050 .13 \\
\hline$\sigma_{v}$ & 0.1 & $\infty$ & i. gamma & 0.11 & 0.090 .13 & 0.13 & 0.110 .14 \\
\hline$\sigma_{d}^{E A}$ & 0.3 & $\infty$ & i. gamma & 0.20 & 0.150 .26 & & \\
\hline$\sigma_{f}^{E A}$ & 0.2 & $\infty$ & i. gamma & 0.20 & 0.150 .25 & & \\
\hline$\sigma_{d}^{U S A}$ & 0.5 & $\infty$ & i. gamma & & & 0.45 & 0.360 .55 \\
\hline$\sigma_{f}^{U S A}$ & 0.6 & $\infty$ & i. gamma & & & 0.59 & 0.490 .69 \\
\hline
\end{tabular}

Note: Own calculations 
Table 4: Estimated Parameters - Baseline Variant

\begin{tabular}{|c|c|c|c|c|c|c|c|}
\hline par. & $\begin{array}{l}\text { prior } \\
\text { mean }\end{array}$ & $\begin{array}{l}\text { prior } \\
\text { s.d. }\end{array}$ & $\begin{array}{l}\text { prior } \\
\text { dist. }\end{array}$ & $\begin{array}{l}\text { post. } \\
\text { mean } \\
\text { EA } 12\end{array}$ & $\begin{array}{c}90 \% \text { conf. } \\
\text { interval } \\
\text { EA } 12\end{array}$ & $\begin{array}{l}\text { post. } \\
\text { mean } \\
\text { USA }\end{array}$ & $\begin{array}{c}90 \% \text { conf. } \\
\text { interval } \\
\text { USA }\end{array}$ \\
\hline$\sigma$ & 1.0 & 0.5 & gamma & 1.26 & 0.531 .98 & 1.60 & 0.752 .41 \\
\hline$\phi$ & 1.0 & 0.5 & gamma & 1.30 & 0.452 .09 & 1.35 & 0.502 .16 \\
\hline$h$ & 0.7 & 0.1 & beta & 0.80 & 0.710 .90 & 0.76 & 0.660 .86 \\
\hline$\alpha$ & 0.33 & 0.1 & beta & 0.34 & 0.180 .49 & 0.42 & 0.270 .56 \\
\hline$\theta_{p}$ & 0.7 & 0.05 & beta & 0.75 & 0.690 .81 & 0.77 & 0.720 .83 \\
\hline$\theta_{w}$ & 0.75 & 0.05 & beta & 0.81 & 0.760 .87 & 0.83 & 0.780 .88 \\
\hline$\delta_{p}$ & 0.5 & 0.2 & beta & 0.23 & 0.030 .41 & 0.15 & 0.030 .27 \\
\hline$\delta_{w}$ & 0.5 & 0.2 & beta & 0.19 & 0.050 .33 & 0.15 & 0.030 .26 \\
\hline$\psi_{\pi}$ & 1.5 & 0.15 & gamma & 1.40 & 1.171 .64 & 1.40 & 1.181 .61 \\
\hline$\psi_{y}$ & 0.2 & 0.15 & gamma & 0.19 & 0.080 .30 & 0.14 & 0.050 .23 \\
\hline$\rho_{i}$ & 0.8 & 0.05 & beta & 0.90 & 0.860 .93 & 0.92 & 0.900 .94 \\
\hline$\rho_{u}$ & 0.5 & 0.2 & beta & 0.76 & 0.640 .88 & 0.89 & 0.830 .96 \\
\hline$\rho_{d}$ & 0.5 & 0.2 & beta & 0.24 & 0.040 .43 & 0.22 & 0.060 .37 \\
\hline$\rho_{f}$ & 0.5 & 0.2 & beta & 0.24 & 0.070 .41 & 0.19 & 0.060 .31 \\
\hline$\sigma_{u}$ & 0.1 & $\infty$ & i. gamma & 0.17 & 0.100 .24 & 0.09 & 0.050 .13 \\
\hline$\sigma_{v}$ & 0.1 & $\infty$ & i. gamma & 0.11 & 0.090 .12 & 0.13 & 0.110 .14 \\
\hline$\sigma_{d}^{E A}$ & 0.3 & $\infty$ & i. gamma & 0.24 & 0.180 .31 & & \\
\hline$\sigma_{f}^{E A}$ & 0.2 & $\infty$ & i. gamma & 0.21 & 0.160 .26 & & \\
\hline$\sigma_{d}^{U S A}$ & 0.5 & $\infty$ & i. gamma & & & 0.50 & 0.400 .61 \\
\hline$\sigma_{f}^{U S A}$ & 0.6 & $\infty$ & i. gamma & & & 0.59 & 0.490 .70 \\
\hline
\end{tabular}

Note: Own calculations 
Figure 1: Impulse-Response Functions, EA 12, Habit vs No Habit

(solid line-habit formation, no indexation; dashed line- no habit formation, no indexation)
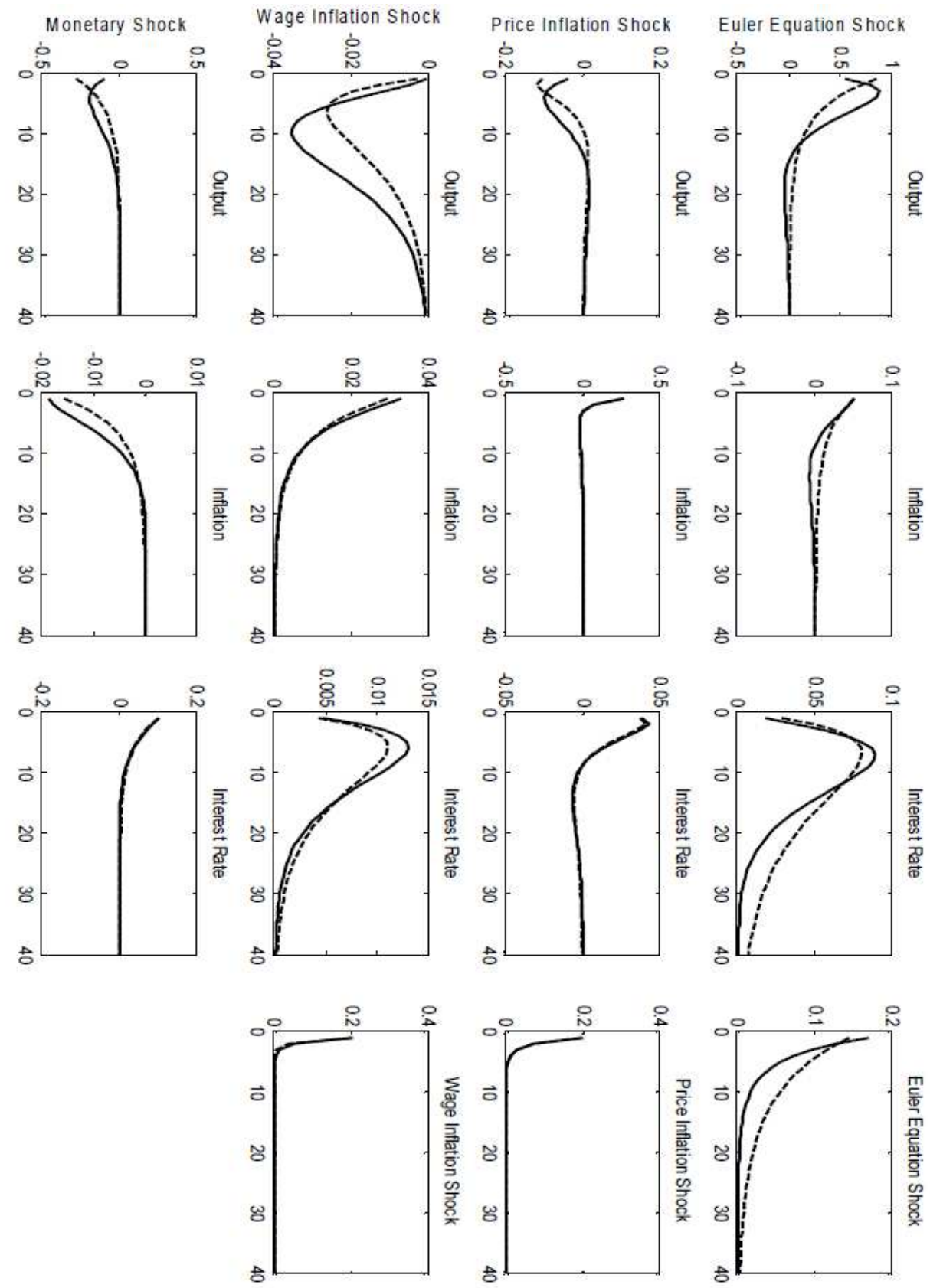
Figure 2: Impulse-Response Functions, EA 12, No Indexation vs Partial Indexation (solid line - no indexation, habit formation; dashed line - price and wage indexation, habit formation; dotted line - wage indexation, habit formation; dashed and dotted line price indexation, habit formation)
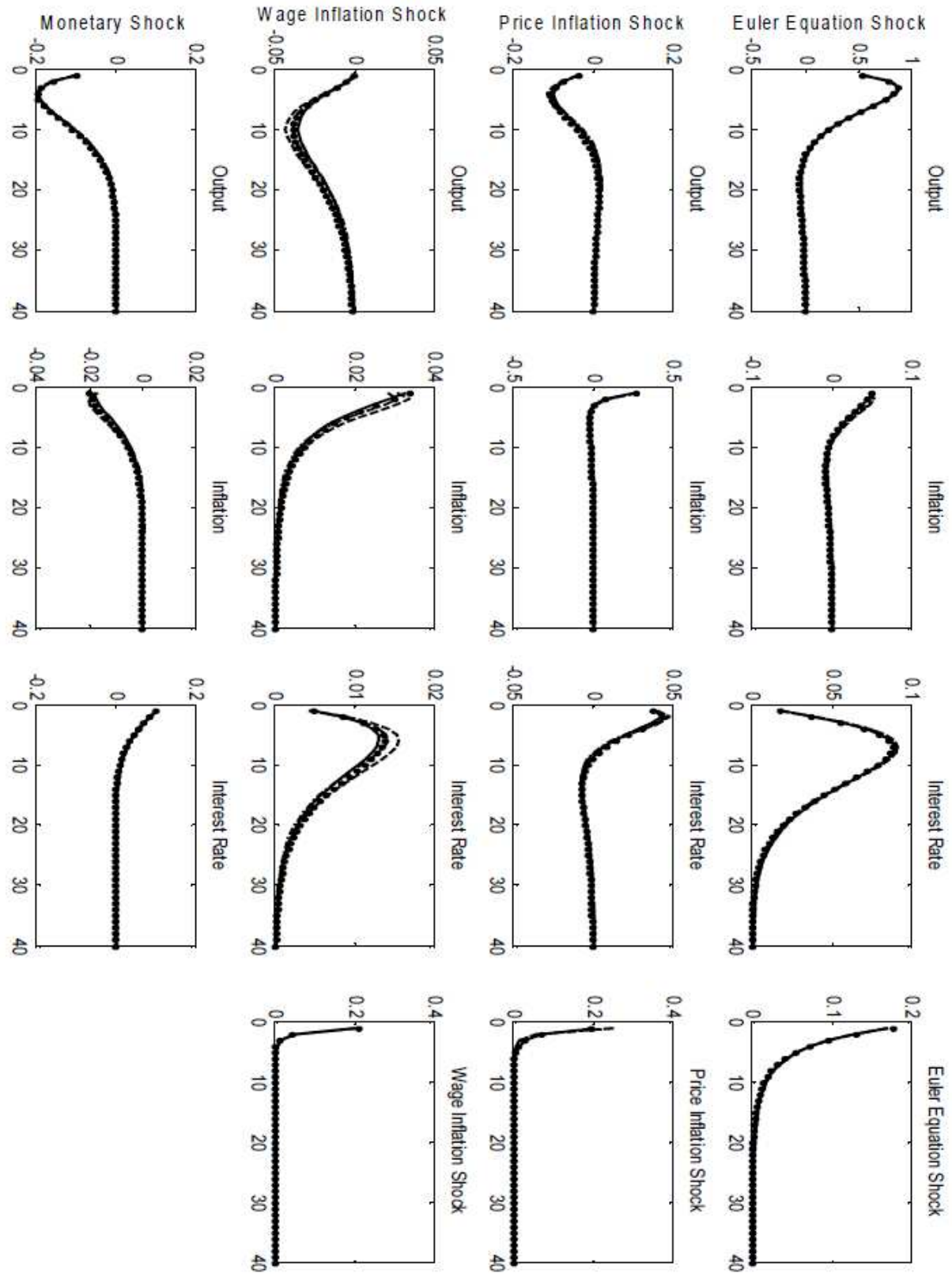